\title{
Excretion kinetics of urinary metabolites in a patient addicted to trichloroethylene
}

\author{
MASAYUKI IKEDA ${ }^{1}$, HATSUE OHTSUJI ${ }^{1}$, HITOSHI KAWAI $^{2}$, and \\ MASAICHI KUNIYOSHI ${ }^{3}$ \\ Kyoto University Faculty of Medicine and Higashiyama-Kogen Sanatorium, Kyoto, Japan
}

\begin{abstract}
Ikeda, M., Ohtsuji, H., Kawai, H., and Kuniyoshi, M. (1971). Brit. J. industr. Med., 28, 203-206. Excretion kinetics of urinary metabolites in a patient addicted to trichloroethylene. A male Japanese subject, single, aged 38, who worked at a workshop washing metal parts with trichloroethylene, was admitted to our clinic due to addiction to the solvent. Analyses of urine revealed the presence of up to $160 \mu \mathrm{g} / \mathrm{ml}$ of trichloro-compounds (mostly trichloroacetic acid) which gradually disappeared in three weeks as the psychotic symptoms cleared up. The excretion half-lives of trichloroethylene metabolites for the initial rapid phase (succeeding slow phase in parentheses) were 5.8 (49.7) hours for trichloroethanol, 22.5 (72.6) hours for trichloroacetic acid, and $7 \cdot 5(72 \cdot 6)$ hours for total trichloro-compounds.
\end{abstract}

Increasing attention has been paid recently to the abuse of drugs which may cause toxic psychosis (Bewley, 1967). Among these is trichloroethylene, which is widely used in industry as a degreasing solvent (Browning, 1965). Although cases of addiction to this substance have been reported since 1927 (Baader, 1927), the metabolic approach to this addiction has not hitherto received attention.

In this paper, we report on a patient who had been working with trichloroethylene in a degreasing workshop and who became addicted after habitually sniffing the solvent. The main metabolic pathways of trichloroethylene have been previously summarized (Tanaka and Ikeda, 1968).

${ }^{1}$ Department of Public Health, Kyoto University Faculty of Medicine, Kyoto, Japan.

'Department of Psychiatry, Kyoto University Hospital, Kyoto, Japan.

${ }^{3}$ Department of Psychiatry, Higashiyama-Kogen Sanatorium, Kyoto, Japan.

Reprint requests: Masayuki Ikeda, Department of Public Health, Kyoto University Faculty of Medicine, Kyoto, Japan.

\section{Materials and methods}

Urine for analysis was obtained either by catheterization or by voiding immediately after wakening in the morning.

The amounts of the following substances in urine were determined: trichloroacetic acid, trichloroethanol, and total trichloro-compounds (Tanaka and Ikeda, 1968), conjugated glucuronide (Ikeda, 1964), and creatinine (Ikeda and Ohtsuji, 1969).

The elimination half-life ( $\left.\mathrm{T} \frac{1}{2}\right)$ of the metabolite in urine was determined from the regression line fitted by the least square method.

\section{Case report}

A 38-year-old single Japanese male had worked for 11 years in a small firm where he washed metal parts of electric apparatus by dipping them into a trichloroethylene bath at room temperature. The environmental concentration of trichloroethylene was unknown. He stated that when he felt very tired or had difficulty in sleeping he had been in the habit of sniffing a cloth soaked in trichloroethylene up to three times daily for six to eight years. Since the middle of May his family had pressed him to stop the habit. On 30 May he complained of severe pain in the left lumbar region and was admitted to a local hospital with suspected volvulus until the pain 
disappeared. On the night of 1 June, the day of discharge from the local hospital, and on the following two days, he was nervous and timid as if 'somebody is coming'. This caused his family to send him to our University clinic.

Examination at the University psychiatric clinic on 4 June revealed disorientation, visual hallucinations, and delusions of persecution. The case was diagnosed as exogenous psychosis possibly due to trichloroethylene addiction. Other main signs and laboratory findings were: light reflex, slow and imperfect; finger tremor; Romberg's sign positive; serum Wassermann reaction negative; liver function tests, including serum alanine aminotransferase, alkaline phosphatase, thymol turbidity test, and $A / G$ ratio, normal.

The patient was treated with intravenous infusion of $5 \%$ glucose, Ringer's solution, and a vitamin mixture for 10 days. No other medicine was administered. In three days he became reorientated and within a week the tremor had disappeared and normal gait was regained. Hallucinations and delusions of persecution ceased in the middle of June after an outburst of agitation on the night of 9 June. The patient became mentally normal at the end of June and was allowed to leave the hospital on 5 July. After recovery he had only imperfect memory of the illness.

\section{Laboratory investigations}

Excretion of trichloroethylene metabolites in urine The urinary levels of the metabolites were followed from the day of admission to our clinic (i.e., five days after the discontinuation of trichloroethylene sniffing). The results of the analysis are summarized in Figure 1. The concentration of total trichloro-compounds (i.e., trichloroacetic acid plus trichloroethanol) decreased linearly when plotted in a semilogarithmic graph but it took more than three weeks to return to the normal level of less than $1 \mathrm{mg} / \mathrm{l}$. (Ikeda and Ohtsuji, 1969). Trichloroacetic acid accounted for more than $90 \%$ of the total trichloro-compounds. The trichloroethanol concentration also decreased exponentially (Fig. 1A), but at a faster rate than did the trichloroacetic acid or total trichlorocompounds. Essentially, only trichloroacetic acid was being excreted 10 days after admission. The ratio, trichloroethanol: trichloroacetic acid, was $1: 10$ or less (Fig. 1A), which was much lower than the ratio of 1 to 2:1 observed in healthy factory workers exposed to trichloroethylene (10 to $30 \mathrm{ppm}, 8$ hours daily) (Ikeda and Ohtsuji, unpublished observation), or the ratio of 10:1 in a case of accidental exposure in which a male worker was exposed to 400 to $750 \mathrm{ppm}$ of trichloroethylene and

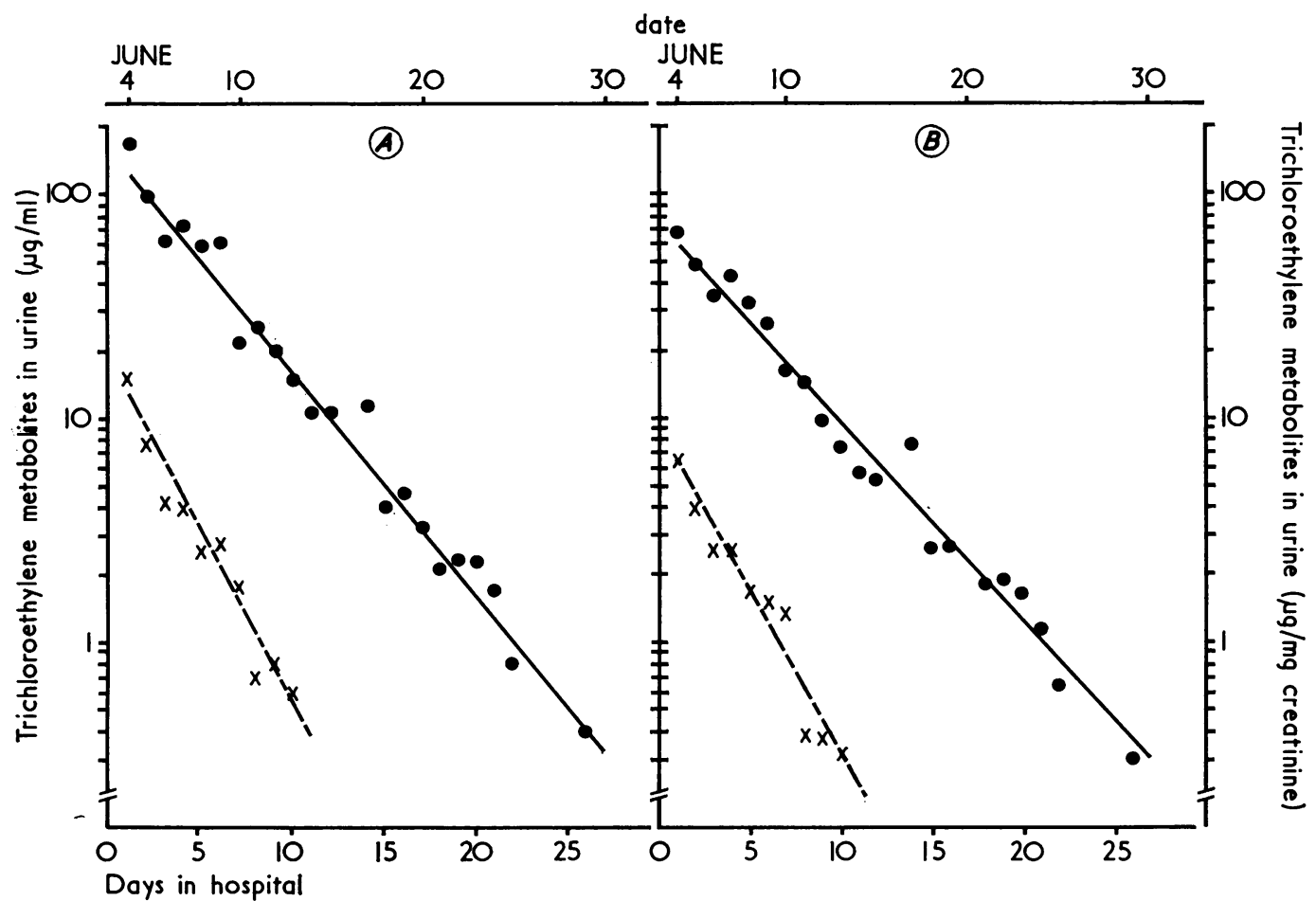

FIG. 1. Excretion of trichloroethylene metabolites in urine. $(A)$ Observed values. (B) Values corrected with creatinine concentration. total trichloro-compounds (i.e., trichloroacetic acid plus trichloroethanol); $\times$ trichloroethanol. 
fell in a faint (Ikeda and Ohtsuji, unpublished observation). This led us to suspect that our present patient might have metabolic difficulties in converting trichloroethylene to trichloroethanol. About a month later, when the level of total trichloro-compounds had returned to normal, the patient was given an inhalation of trichloroethylene vapour (containing about $0.3 \mathrm{~g}$ of trichloroethylene) and the excretion of metabolites in the urine was studied. The results (Fig. 2A) showed that trichloroacetic acid and trichloroethanol were excreted and that the trichloroethanol:trichloroacetic acid ratio in this case was as high as 13:1 when the concentrations reached their peaks.

A negative test for deletion of glucuronide conjugation To examine the possibility that the unusual trichloroethanol:trichloroacetic acid ratio might be due to a defect of glucuronide conjugation, the patient was given $1 \mathrm{~g}$ of salicylamide orally and the urinary level of conjugated glucuronide (supposedly ethereal glucuronide of salicylamide as described by Mandel, Rodwell, and Smith (1952)) was determined. The level of conjugated glucuronide increased markedly, and more than $50 \%$ of the dose given was excreted into urine as conjugated glucuronide within 6 hours of the administration as reported by Levy and Matsuzawa (1967), indicating that the patient probably had a normal ability to conjugate foreign compounds with glucuronic acid.

\section{Discussion}

To exclude the possibility of fluctuation in metabolite levels due to change in urine concentration, the metabolite levels were corrected with creatinine concentration and the results were re-analysed in terms of metabolite/creatinine ratio as shown in Figures 1B and 2B. It is apparent that the exponential decline in metabolite concentration occurred with both uncorrected and corrected values.

The elimination half-lives of urinary metabolites are summarized in the Table. As in the case of other drugs (Wagner and Northam, 1967; Levy and Miller, 1965; Levy and Jusko, 1966), the kinetics of

\section{TABLE}

URINARY EXCRETION HALF-LIFE OF TRICHLOROETHYLENE METABOLITES DURING SHORT- AND LONG-TERM EXCRETION

\begin{tabular}{|c|c|c|c|}
\hline Metabolites & $\begin{array}{c}A \\
\text { Rapid } \\
\text { phase } \\
\text { Observed } \\
\left.\text { (Corrected }^{1}\right) \\
\text { (hou }\end{array}$ & $\begin{array}{c}\text { B } \\
\text { Slow } \\
\text { phase } \\
\text { Observed }^{\text {Observed }} \\
\left(\text { Corrected }^{1}\right) \\
\text { urs })\end{array}$ & $\begin{array}{c}\text { Ratio } \\
\text { B/A } \\
\text { Observed }^{1} \\
\left.\text { Corrected }^{1}\right)\end{array}$ \\
\hline $\begin{array}{l}\text { Trichloroethanol } \\
\text { Trichloroacetic acid } \\
\text { Total trichloro- } \\
\text { compounds }\end{array}$ & $\begin{array}{rr}5 \cdot 8 & (6 \cdot 1) \\
22 \cdot 5 & (27 \cdot 5) \\
& \\
7 \cdot 5 \quad(8 \cdot 7)\end{array}$ & $\begin{array}{l}49.7(49.8) \\
72.6(95.0) \\
\\
72.6(95.0)\end{array}$ & $\begin{array}{l}8 \cdot 6(7 \cdot 6) \\
3 \cdot 2(3 \cdot 1) \\
9 \cdot 8(9 \cdot 5)\end{array}$ \\
\hline
\end{tabular}

${ }^{1}$ Corrected with creatinine concentration, i.e., half-life was calculated from the ratios of metabolite/creatinine.
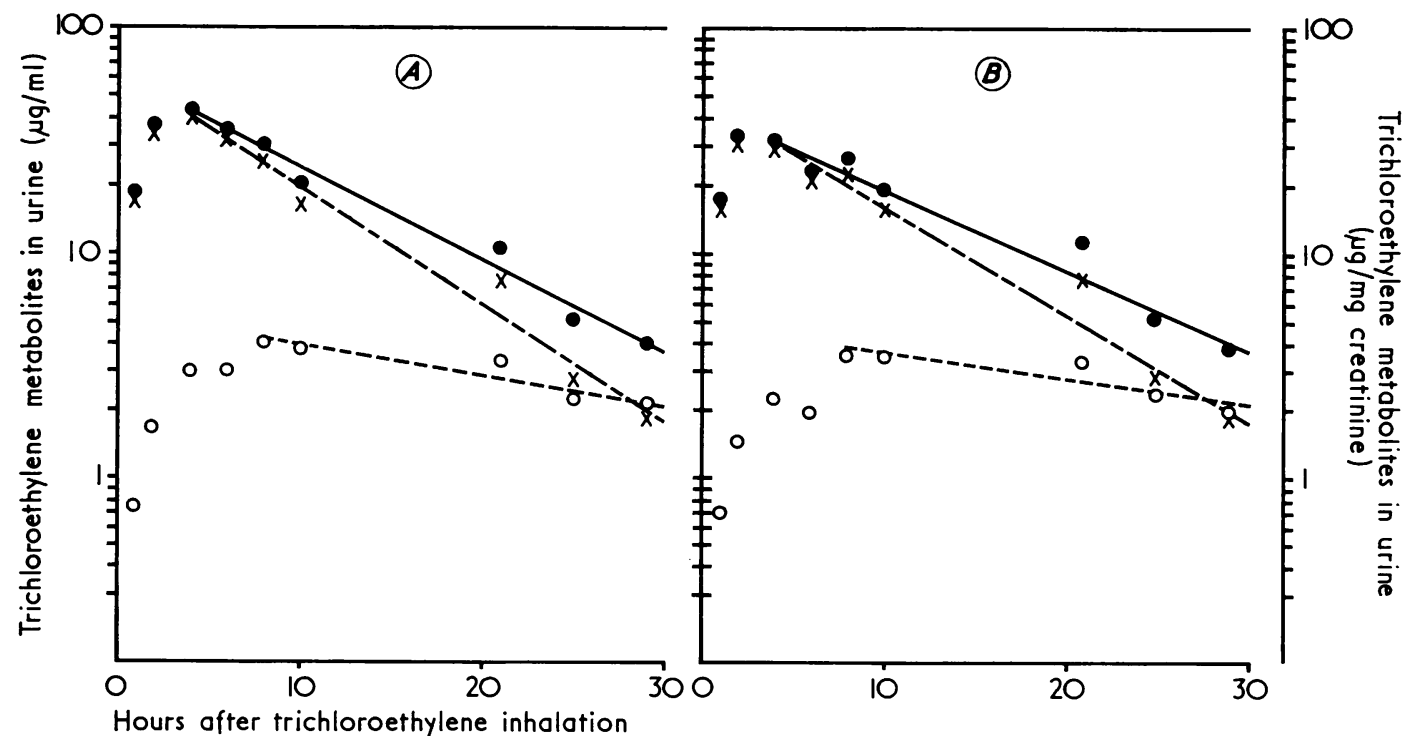

FIG. 2. Urinary excretion of trichloroethylene metabolites after experimental trichloroethylene inhalation. (A) Observed values. $(B)$ Values corrected with creatinine concentration. The patient was given an inhalation of about $0 \cdot 3 \mathrm{~g}$ trichloroethylene. total trichloro-compounds (i.e., trichloroacetic acid plus trichloroethanol); $\times$ trichloroethanol; $\bigcirc$ trichloroacetic acid. 
excretion of trichloroethylene metabolites may consist of two components, an initial rapid phase and a succeeding slow phase. The fast fall of excretion of urinary metabolites immediately after the experimental inhalation of trichloroethylene (Fig. 2A and B) represents the initial rapid phase while the decrease five days after the discontinuation of trichloroethylene sniffing (Fig. 1A and B) corresponds to the succeeding slow phase; $\mathrm{T}_{2} \frac{1}{2}$ for the rapid phase shown in column $\mathrm{A}$ in the Table is smaller than $\mathrm{T}_{2}^{\frac{1}{2}}$ for the slow phase in column B. $\mathrm{T} \frac{1}{2}$ for trichloroacetic acid is larger than that for trichloroethanol in both columns $\mathrm{A}$ and $\mathrm{B}$, and the ratio of $\mathrm{B} / \mathrm{A}$ for trichloroacetic acid is about 3 while that for trichloroethanol is 8 , indicating that the excretion of trichloroacetic acid takes longer than the excretion of trichloroethanol, as reported by Soucěk and Vlachová (1960), Bartonícěk (1962), and Bartonícěk and Teisinger (1962). In other words, the ratio of trichloroethanol : trichloroacetic acid varies as a function of time after the cessation of exposure to trichloroethylene and, therefore, the level of total trichloro-compounds (i.e., trichloroethanol plus trichloroacetic acid) in urine is a better index of exposure than that of trichloroacetic acid alone (Tanaka and Ikeda, 1968).

It is noteworthy that the disappearanceof psychotic symptoms coincided with the fall in urinary levels of trichloroethylene metabolites, although there is no positive finding indicating that trichloroethylene or its metabolite actually causes psychotic symptoms.

Thanks are due to Professor M. Nishio of the Department of Public Health, Kyoto University Faculty of Medicine, Kyoto, Japan, for his support and interest.

This work has been supported in part by a research grant from the Ministry of Education of the Japanese Government to one (M.I.) of the authors and a research grant from Fujiwara Memorial Foundation.

\section{References}

Baader, E. W. (1927). Tätigkeitsbericht der Abteilung für Gewerbekrankheiten des Kaiserin Auguste-ViktoriaKrankenhauses in Berlin-Lichtenberg. Zbl. Gewerbehyg., 14, 385-393.

Bartonícek, V. (1962). Metabolism and excretion of trichloroethylene after inhalation by human subjects. Brit. $J$. industr. Med., 19, 134-141.

- and Teisinger, J. (1962). Effect of tetraethyl thiuram disulphide (disulfiram) on metabolism of trichloroethylene in man. Brit. J. industr. Med., 19, 216-221.

Bewley, T. H. (1967). Drug addiction. Brit. med. J., 3, $603-$ 605.

Browning, E. (1965). Toxicity and Metabolism of Industrial Solvents, pp. 189-212. Elsevier, Amsterdam and London.

Ikeda, M. (1964). Enzymatic studies on benzene intoxication. J. Biochem. (Tokyo), 55, 231-243.

and Ohtsuji, H. (1969). Hippuric acid, phenol, and trichloroacetic acid levels in the urine of Japanese subjects with no known exposure to organic solvents. Brit. J. industr. Med., 26, 162-164.

Levy, G., and Jusko, W. J. (1966). Factors affecting the absorption of riboflavin in man. J. pharm. Sci., 55, 285289.

— and Matsuzawa, T. (1967). Pharmacokinetics of salicylamide elimination in man. J. Pharmacol. exp. Ther., 156, 285-293.

—_ and Miller, K. E. (1965). Drug absorption and exsorption kinetics in goldfish. J. pharm. Sci., 54, 1319-1325.

Mandel, H. G., Rodwell, V. W., and Smith, P. K. (1952). A study of the metabolism of $C^{14}$ salicylamide in the human. J. Pharmacol. exp. Ther., 106, 433-439.

Soucek, B., and Vlachová, D. (1960). Excretion of trichloroethylene metabolites in human urine. Brit.J. industr. Med., 17, 60-64.

Tanaka, S., and Ikeda, M. (1968). A method for determination of trichloroethanol and trichloroacetic acid in urine. Brit. J. industr. Med., 25, 214-219.

Wagner, J. G., and Northam, J. I. (1967). Estimation of volume of distribution and half-life of a compound after rapid intravenous injection. J. pharm. Sci., 56, 529-531.

Received for publication July 22, 1970. 